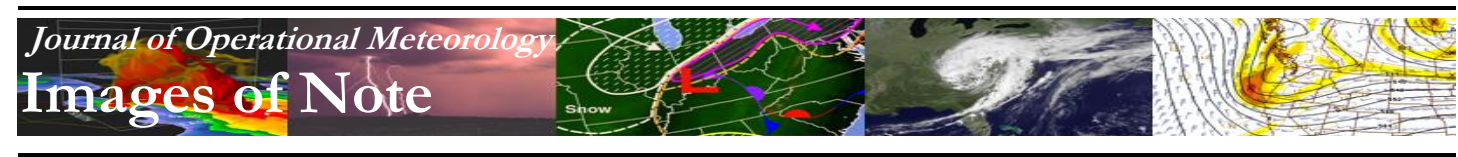

\title{
A Swirl in the Clouds near Santa Cruz Island
}

\author{
BRADLEY M. MULLER and CHRISTOPHER G. HERBSTER \\ Embry-Riddle Aeronautical University, Daytona Beach, Florida \\ (Manuscript received 8 January 2015; review completed 4 March 2015)
}

\section{Introduction}

On 16 July 2006, a commercial pilot flying a coastal route between Anaheim and San Francisco, California, observed and photographed a cyclonic swirl in the stratus clouds near Santa Cruz Island (Fig. 1). This photograph was provided by a colleague of the pilot, with an inquiry as to what these unusual cloud formations might be (Capt. P. Weiss 2006, personal communication; see also Muller et al. 2015). This paper aims to answer that question as well as to present this unusual image and discuss the meteorology of the phenomenon depicted.

The photographed swirl (Fig. 1) is an atmospheric eddy produced by marine atmospheric boundary layer (MABL) flow past terrain. Such eddies form as part of an atmospheric wake phenomenon in the lee of islands and headlands that penetrate the inversion above the MABL (Chopra and Hubert 1965; Etling 1989; Young and Zawislak 2006). Mesoscale eddies have been detected in satellite imagery in marine stratocumulus clouds since the first successful weather satellite was launched in 1960 (Bowley et al. 1962; Hubert and Krueger 1962). In some cases two counter-rotating vortices are formed downwind of the terrain obstructions to the flow, and stay attached to the terrain (e.g. Smolarkiewicz and Rotunno 1989; Schär and Smith 1993a, hereafter SS93a). In other cases an alternating series of counter-rotating vortices form and shed, moving downwind with the mean MABL flow (Schär and Smith 1993b). Some researchers consider these circulations to be the atmospheric analog of von Kármán vortex streets that appear as fluids flow past bluff bodies (Chopra and Hubert 1965; Ruscher and Deardorff 1982; Young and Zawislak 2006).
Operational meteorologists viewing geostationary satellite imagery of the west coast of North America can expect to see atmospheric eddies frequently in the vicinity of the Channel Islands of southern California when stratus or marine stratocumulus clouds are present. Interestingly, however, to our knowledge, the case presented here is only the second close-up photograph of a marine stratocumulus eddy taken from an airplane to appear in publication (Muller et al. 2015). These features are operationally significant in that they have been implicated in mixing at the coastal margin - namely, cross-inversion fluxes of ozone and momentum (Lester 1985). Anecdotal reports suggest an environment of strong aircraft turbulence in the lee of islands that produce similar eddies (B. Baxter 2012 and P. Ruscher 2012, personal communications). Indeed, turbulence in the lee of the Hawaiian island of Kauai was documented as a cause of the breakup and crash of NASA's ultralight unmanned aerial vehicle Helios (Porter et al. 2007). Furthermore, model studies suggest that turbulence in hydraulic jumps is an essential process in wake eddy formation and the amplification of vorticity (SS93a; Schär and Durran 1997).

\section{Discussion}

The eddy photograph (Fig. 1) was taken at 1126 PDT (1826 UTC) looking toward Santa Cruz Island to the west-southwest. Figure 2 shows corresponding Geostationary Operational Environmental Satellite (GOES) visible satellite images. The satellite image from 1830 UTC (Fig. 2) is a close match to the aerial photograph (Fig. 1) in terms of cloud feature morphology. Several of the same features can be seen 


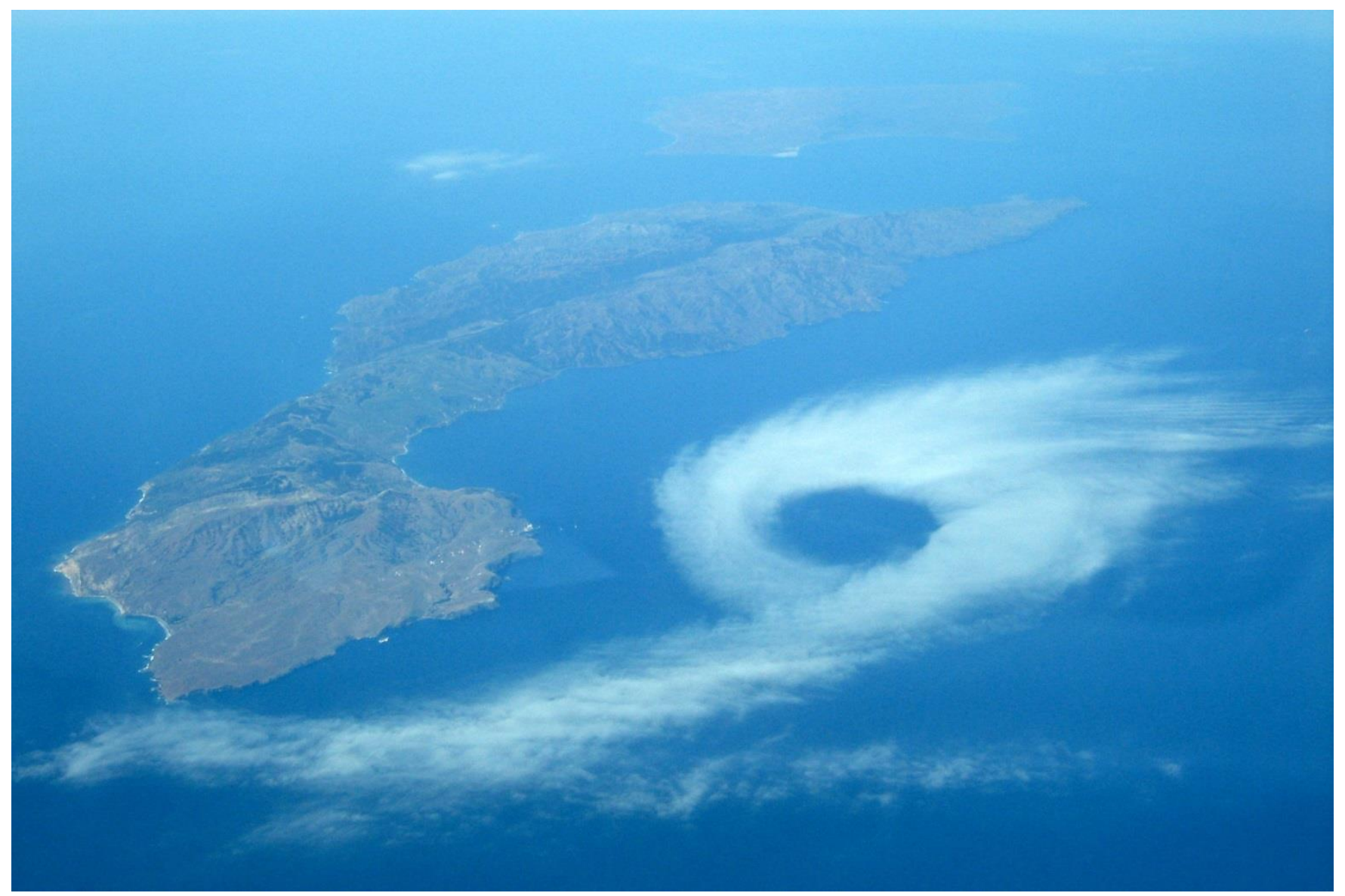

Figure 1. Aerial photograph of a stratocumulus cloud vortex just north of Santa Cruz Island on 16 July 2006 at 1126 PDT (1826 UTC), viewing toward the southwest. (Photo by "KB" courtesy of Capt. P. Weiss of SkyWest Airlines). Click image for an external version; this applies to all figures hereafter.

in both the satellite (Fig. 2) and the photographic (Fig. 1) images, including the tongue of clouds extending from the tip of Santa Cruz Island toward the eddy, striations in the stratus clouds on the northwestern side of the eddy, and the circular, cloud-free eye. Analysis of the 1830 UTC satellite image indicates that the circulation had a width of 9-10 km and length of 25 $\mathrm{km}$, thus straddling the line between the meso-gamma $(2-20 \mathrm{~km})$ and meso-beta $(20-200 \mathrm{~km})$ scales (Orlanski 1975). The cloud-free eye was $3 \mathrm{~km}$ in diameter.

The synoptic situation at the surface on 16 July 2006 presented an overall onshore pressure gradient resulting in northwesterly flow over the ocean west of much of California including over the westernmost Channel Island (San Miguel). However, a weak low pressure center, possibly the center of a meso-beta scale coastal circulation generically referred to as a Catalina eddy (e.g., Bosart 1983), was analyzed just northwest of Santa Cruz Island on the National
Centers for Environmental Prediction North American surface analyses for 0600 UTC and 0900 UTC (not shown). Resulting persistent southeasterly surface flow over Santa Cruz Island synoptically set the stage for the formation of the smaller photographed eddy north of the island. The 550-m terrain in the eastern part of Santa Cruz Island extended into a strong temperature inversion of $10^{\circ} \mathrm{C}$ above the MABL.

Early researchers explained similar eddies as a two-dimensional horizontal frictional phenomenon of lateral boundary layer separation (Chopra and Hubert 1965; Jensen and Agee 1978), in analogy to von Kármán vortex streets. However, more recent theoretical and modeling results showed that the formation of lee eddies can occur even in the absence of surface friction (Smolarkiewicz and Rotunno 1989; SS93a; Schär and Durran 1997; Epifanio and Durran 2002) and that three-dimensional motions that promote vorticity tilting and stretching are involved (see Young and Zawislak 2006 for a more complete review). 

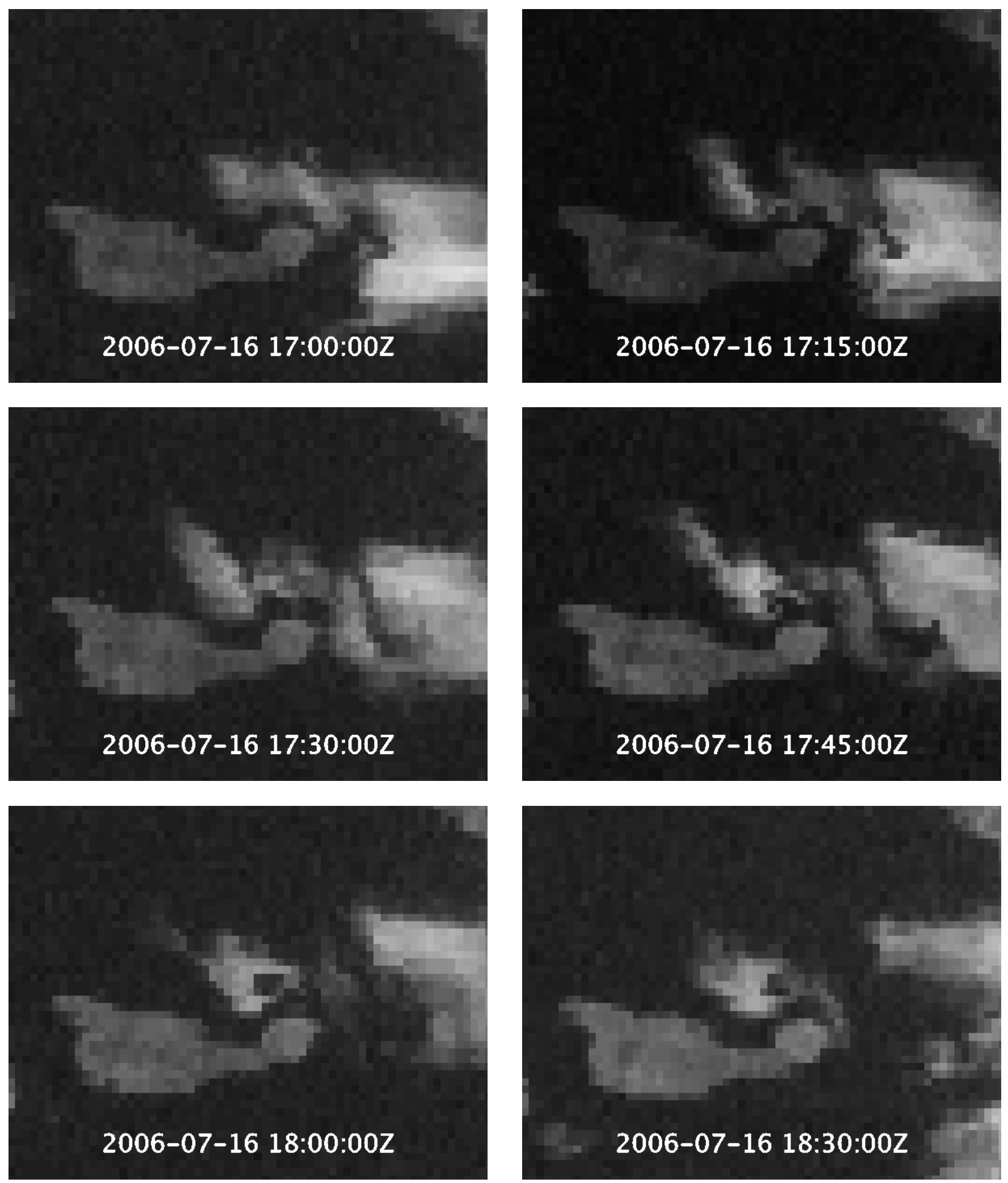

Figure 2. GOES-West visible satellite images from 1700 UTC to 1830 UTC on 16 July 2006. In this sequence, dry, cloud-free air in the lee of Santa Cruz Island can be seen moving laterally into the circulation followed by a tongue of clouds wrapping around and closing off the eye. The satellite image from 1830 UTC shows the same cloud as Fig. 1. North is "up" or toward the top of the page (cf. Fig. 1). 
Epifanio and Rotunno (2005) and SS93a emphasized the importance of flow-blocking in the formation of wake eddies. Their simulations delineated a basic sequence of events that can be applied to the MABL: flow is blocked by a terrain obstacle, leaving a shallower MABL on its lee side, directly behind it with respect to the direction of the undisturbed flow (in this case, the northern side of the island). Gravity causes an airflow reversal directly in the lee of the obstacle, from the deeper MABL farther downstream back toward the shallower MABL at the base of terrain. Shear lines of enhanced vorticity trail downstream off of the lateral edges of the obstruction, dividing the reversed wake flow from the background, undisturbed winds, and occasionally eddies come spinning off from those lateral edges along the lines of strong shear.

The sequence of satellite images in Fig. 2 is consistent with the above description of eddy formation. Initially, from 1700 UTC to 1730 UTC a band of clouds wrapping around the northeastern periphery of Santa Cruz Island is apparent, with a clear slot between the clouds and the lee (northern) slopes of the island, suggesting that dry air is sliding downslope between the circulation center and the terrain. Subsequently at 1745 UTC a tongue of clouds moves eastward as part of the reversed (west-northwesterly) wake flow, surrounding an inclusion of the dry air that becomes the cloud-free eye. Weather Research and Forecasting (WRF) model simulations conducted for the current research suggest that this air had previously descended adjacent to the island slope. The tongue of eastward-moving clouds ultimately connected into a ring, thereby pinching off the cloud-free eye of previously descended drier air. Thus, the dry air comprising the cloud-free eye of the eddy apparently was wrapped laterally into the circulation after its descent. The WRF simulations also corroborate that the eddy formed at the shear line between the westnorthwesterly wake flow immediately north of Santa Cruz Island and the southeasterly background flow sweeping around its northeastern periphery, and suggest that the northwesterly wake flow may have been reinforced by return of the more climatologically typical synoptic-scale northwesterly flow to the California Bight. Backwards air parcel trajectories suggest that much of the air within the core of the eddy in the MABL began in the MABL and swept around the eastern end of Santa Cruz Island, but that some air subsided from above the island as air passed over and descended next to the terrain, bringing drier air down into the MABL. In the simulation, some air even descended near the western end of the island into an anticyclonic eddy, becoming trapped in the wake flow, then travelling eastward, and eventually ending up in the simulated cyclonic eddy that appeared similar in many respects to the one photographed by the pilot.

\section{Summary}

This paper has presented an unusual close-up aerial photograph of an eddy circulation in the marine stratus clouds near Santa Cruz Island. Such eddies form in the lee of inversion-penetrating terrain along a shear boundary between the wake flow in the lee of the terrain and the MABL flow around the terrain. The next step in this research is to try to improve the fidelity between the WRF simulations and the observed eddy by running WRF in its large eddy simulation (LES) mode, nested within output from our conventional WRF simulations; it is hoped that the LES will give a better picture of the air flow and internal three-dimensional circulations that are responsible for the specific features evident in the aerial photograph.

Acknowledgments. This research became possible thanks to former Embry-Riddle Aeronautical University (ERAU) student and flight instructor, and current Skywest pilot Captain Peter Weiss, who originally sent us this unique eddy photograph, and his colleague "KB" who photographed the eddy. Fred Mosher assisted with the satellite imagery. We thank Paul Ruscher and Bob Baxter for sharing their personal knowledge and experiences. This research benefited from several government-sponsored programs and software packages: NOAA's CLASS (Comprehensive Large Array-data Stewardship System; www.class.ncdc.noaa.gov/saa/products/welcome) and the McIDAS, GARP, and IDV software packages provided by NSF's Unidata program (www.unidata.ucar.edu/software/). Finally, we thank three anonymous reviewers and the editorial staff at the JOM who made beneficial suggestions for improving the manuscript.

\section{REFERENCES}

Bosart, L. F., 1983: Analysis of a California Catalina eddy event. Mon. Wea. Rev., 111, 1619-1633, CrossRef.

Bowley, C. J., A. H. Glaser, R. J. Newcomb, and R. Wexler, 1962: Satellite observations of wake formation beneath an inversion. J. Atmos. Sci., 19, 52-55, CrossRef.

Chopra, K. P., and L. F. Hubert, 1965: Mesoscale eddies in wake of islands. J. Atmos. Sci., 22, 652-657, CrossRef. 
Epifanio, C. C., and D. R. Durran, 2002: Lee-vortex formation in free-slip stratified flow over ridges. Part II: Mechanisms of vorticity and PV formation in nonlinear viscous wakes. J. Atmos. Sci., 59, 1166-1181, CrossRef.

and R. Rotunno, 2005: The dynamics of orographic wake formation in flows with upstream blocking. $J$. Atmos. Sci., 62, 3127-3150, CrossRef.

Etling, D., 1989: On atmospheric vortex streets in the wake of large islands. Meteor. Atmos. Phys., 41, 157-164, CrossRef.

Hubert, L. F., and A. F. Krueger, 1962: Satellite pictures of mesoscale eddies. Mon. Wea. Rev., 90, 457-463, CrossRef.

Jensen, N. O., and E. M. Agee, 1978: Vortex cloud street during AMTEX 75. Tellus, 30, 517-523, CrossRef.

Lester, P. F., 1985: Studies of the marine inversion over the San Francisco Bay area...a summary of the work of Albert Miller, 1961-1978. Bull. Amer. Meteor. Soc.,66, 1396-1402, CrossRef.

Muller, B. M., C. G. Herbster, and F. R. Mosher, 2015: An unusual aerial photograph of an eddy circulation in marine stratocumulus clouds. Mon. Wea. Rev., 143, 419-432, CrossRef.

Orlanski, I., 1975: A rational subdivision of scales for atmospheric processes. Bull. Amer. Meteor. Soc., 56, 527-530.
Porter, J. N., D. Stevens, K. Roe, S. Kono, D. Kress, and E. Lau, 2007: Wind environment in the lee of Kauai Island, Hawaii during trade wind conditions: weather setting for the Helios mishap. Bound.-Layer Meteor. 123, 463-480, CrossRef.

Ruscher, P. H., and J. W. Deardorff, 1982: A numerical simulation of an atmospheric vortex street. Tellus, 34, 555-566, CrossRef.

Schär, C., and R. B. Smith, 1993a: Shallow-water flow past isolated topography. Part I: Vorticity production and wake formation. J. Atmos. Sci., 50, 1373-1400, CrossRef. and __, 1993b: Shallow-water flow past isolated topography. Part II: Transition to vortex shedding. J. Atmos. Sci., 50, 1401-1412, CrossRef.

and D. R. Durran, 1997: Vortex formation and vortex shedding in continuously stratified flows past isolated topography. J. Atmos. Sci., 54, 534-554, CrossRef.

Smolarkiewicz, P. K., and R. Rotunno, 1989: Low Froude number flow past three-dimensional obstacles. Part I: Baroclinically generated lee vortices. J. Atmos. Sci., 46, 1154-1164, CrossRef.

Young, G. S., and J. Zawislak, 2006: An observational study of vortex spacing in island wake vortex streets. Mon. Wea. Rev., 134, 2285-2294, CrossRef. 